\title{
THE LEVER ARM IN GLENOHUMERAL ABDUCTION AFTER HEMIARTHROPLASTY
}

\author{
A. BONI M. RIETVELD, HEIN A. M. DAANEN, PIET M. ROZING, WILLEM R. OBERMANN
}

From the University Hospital, Leiden, The Netherlands

\begin{abstract}
Fourteen cases of hemiarthroplasty for four-part fractures of the proximal humerus were reviewed. Pain relief was satisfactory, but function was limited, mainly due to loss of glenohumeral abduction despite electromyographic proof of actively contracting abductors in all cases.

Analysis of special radiographs of nine cases showed a direct relationship between the clinical results and the "humeral offset", or distance between the geometric centre of the humeral head and the lateral aspect of the greater tuberosity. This offset affects the lever arms of the glenohumeral abductor muscles. The implications for surgical technique and for the design of shoulder prostheses are discussed.
\end{abstract}

After hemiarthroplasty for displaced four-part fractures of the proximal humerus the range of movement tends to be disappointing. Abduction is usually limited although the shoulders become relatively painless (Marotte, Lord and Bancel 1978; Lim et al. 1983; de Anquin and de Anquin 1984; DesMarchais and Morais 1984; Willems and Lim 1985). We have studied the factors which influence this failure of abduction, in the hope of finding clues for improvement.

\section{PATIENTS AND METHODS}

From 1979 to 1984 a total of 14 patients with displaced four-part fractures of the proximal humerus were treated at the Orthopaedic Department of the University Hospital in Leiden by reconstruction of the proximal humerus with a Neer Type I hemiarthroplasty. There were nine women and five men whose mean age was 65.8 years (range 40 to 81 years). Follow-up times were from 17 months to 7 years (mean 3.2 years). For control studies

A. B. M. Rietveld, MD, Orthopaedic Surgeon

St. Elisabeth's of Groote Gasthuis, Boerhaave Laan 22, 2035 RC Haarlem, The Netherlands.

P. M. Rozing, MD, Professor of Orthopaedic Surgery and Head of Department

W. R. Obermann, MD, Head of Department of Surgical Radiology University Hospital Leiden, Rijnsburgerweg 10, 2333 AA Leiden, The Netherlands.

H. A. M. Daanen, MSc

Orthopaedic Laboratory, State University Leiden, Mezenstraat 2A, 2333 VT Leiden, The Netherlands.

Correspondence should be sent to $\operatorname{Dr}$ A. B. M. Rietveld.

(C) 1988 British Editorial Society of Bone and Joint Surgery 0301-620X/88/4106 $\$ 2.00$

J Bone Joint Surg [Br] 1988;70-B:561-5. we used the unaffected contralateral shoulder of each patient.

Clinical evaluation. Assessment was according to Neer's method (Neer 1970), which allocates 35 points for pain, 30 for function, 25 for range of movement and 10 for radiographic anatomy. An excellent result has over 89 points, satisfactory has over 80 , unsatisfactory has over 70 and failure has below 70 . The presence of significant pain was recorded as a failure.

Radiological evaluation. Using videofluoroscopy, we determined the scapular plane and studied both active and passive shoulder movement. Radiographs were then taken at maximal abduction and half-abduction in the scapular plane and with the arm in a dependent position. The humerus was kept in neutral rotation in relation to the scapular plane throughout the examination. Several parameters related to the shape and position of the head of the humerus were measured and recorded.

Electromyography. During abduction in the scapular plane, EMG recordings were made from 12 shoulder muscles. Wire electrodes were used for the supraspinatus, and surface electrodes for the other muscles. During movement, the abduction angle was monitored by an electronic goniometer attached to the elbow (Vink et al. 1986).

\section{RESULTS}

The results of clinical evaluation are given in Table I. According to the Neer scoring system, two patients had an excellent result, eight were satisfactory and there were four failures; the average score was 76 points. Two patients, both failures, had moderate pain. Even in the 
best results, abduction and flexion were somewhat restricted, while the cases recorded as failures had very poor abduction and flexion. Despite this disappointing range of movement all 14 patients were independent for eating and toilet hygiene. Only seven of the 14 were able to use the arm in an overhead position or to comb their hair.

Nine patients had detailed radiological and electromyographic studies; this group included the two excellent results, three of the eight satisfactory results and all four failures (Table II). Active movement of the glenohumeral joint was less than normal in all the operated shoulders (Freedman and Munro 1966). In three of the failures there was an actual reduction of glenohumeral angle during attempts at abduction. Ankylosis of the glenohumeral joint was excluded since some passive glenohumeral movement was possible in all cases.

There was a remarkable relationship between the clinical result and the range of active glenohumeral abduction (Figs 1 and 2 and Table I). Most abduction was achieved by lateral rotation of the scapula which appeared to be normal in all cases, thus disturbing the normal relationship between scapulothoracic and glenohumeral movements and producing considerable individual variation (Inman, Saunders and Abbott 1944).

The parameters of head shape and position on the radiographs were assessed in relation to the clinical results.

The acromiohumeral interval (A in Fig. 3) showed no correlation.

Medial projection of the humeral head beyond the medial line of the humeral shaft (B in Fig. 3) and the lateral projection of the humeral head at the greater
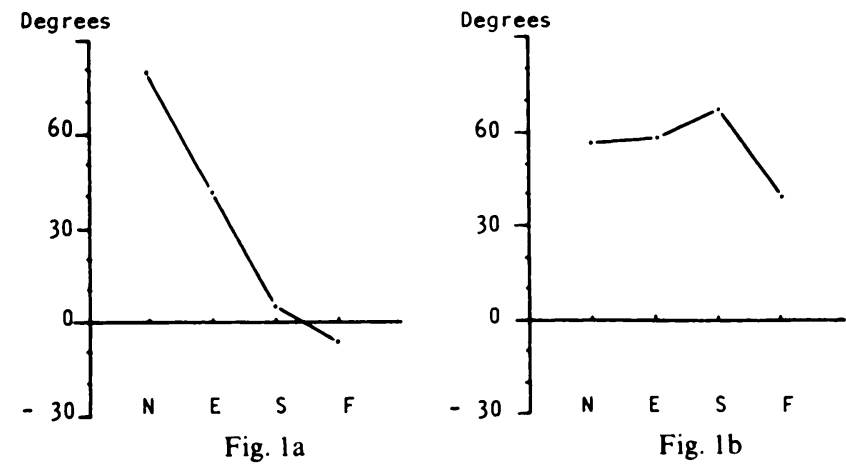

Relation between range of movement and clinical result. Figure la Glenohumeral abduction in the scapular plane. Figure $1 \mathrm{~b}-\mathrm{Scapular}$ rotation during abduction in the scapular plane. $\mathrm{N}$, normal shoulder; $\mathrm{E}$, excellent result of a Neer hemiarthroplasty; $S$, satisfactory result; $F$, failure.

tuberosity in relation to the tip of the acromion (C in Fig. 3) were markedly different between the normal and the operated shoulders, but the measurements did not correlate with the clinical results. In the normal shoulders the greater tuberosity projected an average of $16 \mathrm{~mm}$ laterally, but after arthroplasty the line of the greater tuberosity was medial to the tip of the acromion. The distance between the geometric centre of the humeral head and the lateral side of the greater tuberosity, which we termed the "humeral offset", showed a strong relationship with the range of glenohumeral abduction and therefore with the clinical result (Figs 4, 5 and 6, Table II).

The vertical movement of the geometric centre of the humeral head during active abduction in relation to an axis perpendicular to the glenoid (Poppen and Walker 1976; DesMarchais and Morais 1984) showed excessive upward migration in all the replaced shoulders, but did not relate to the clinical result.

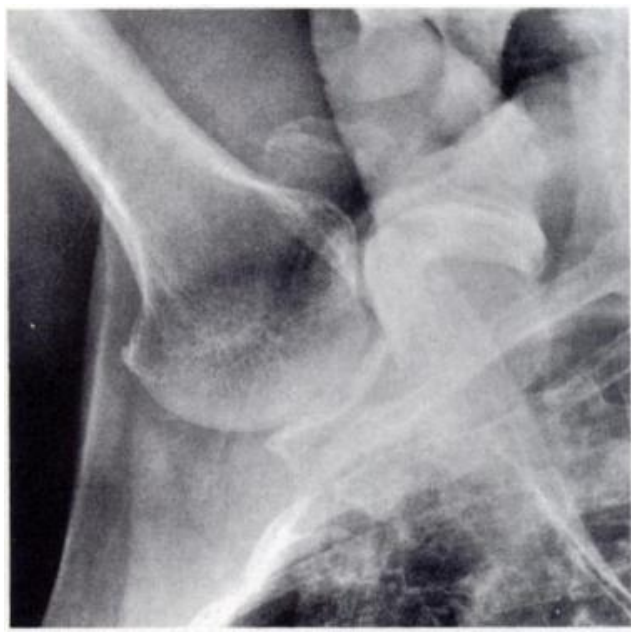

Fig. 2a

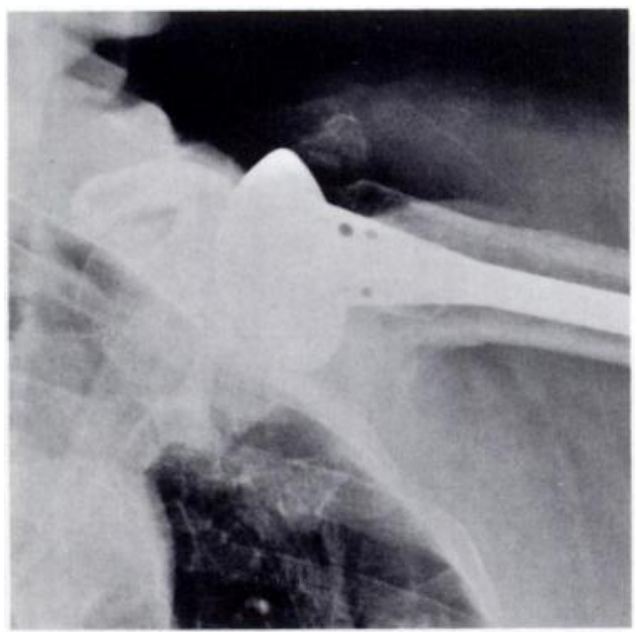

Fig. 2b

Case 1. Maximal abduction in the scapular plane for both arms after a left hemiarthroplasty for four-part fracture. There is limited glenohumeral abduction on the operated side with symmetrical, normal scapular rotation. 


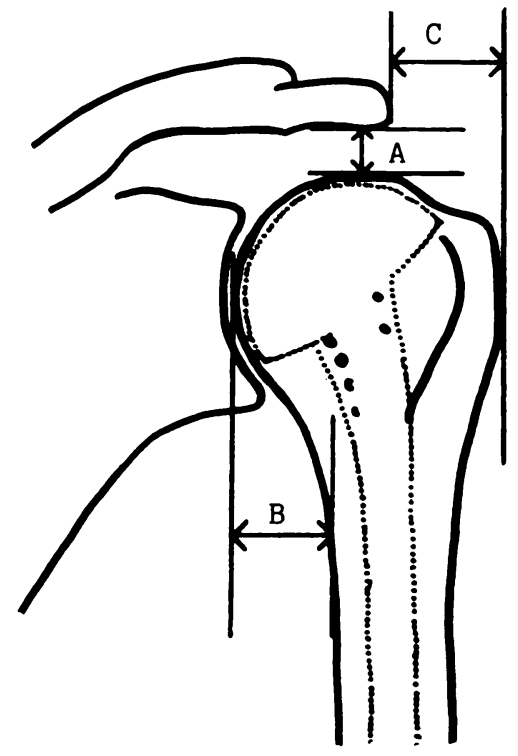

Fig. 3

Parameters of position and shape: $A$, acromio-humeral interval; B, medial projection of humeral head; $C$, lateral projection of greater tuberosity in relation to the acromion.
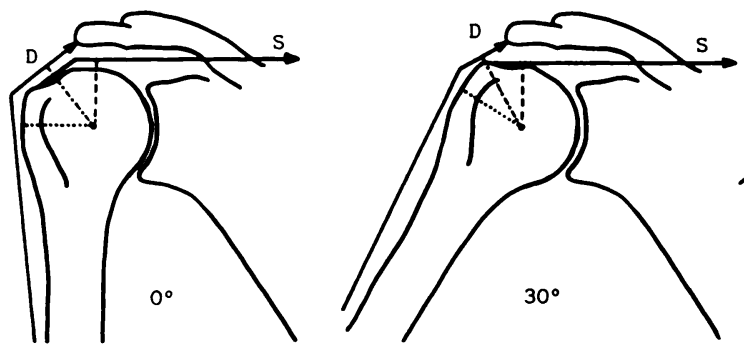

Humeral offset

Lever arm of deltoid
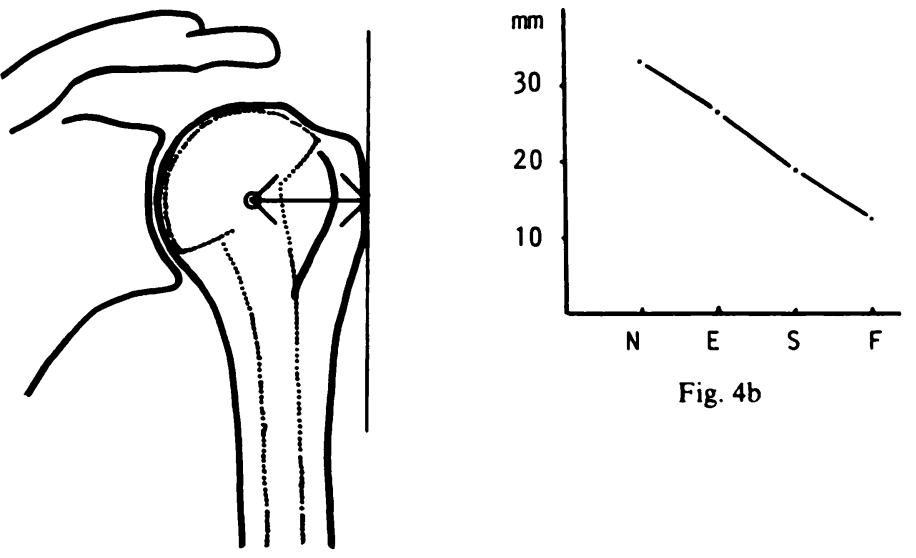

Fig. $4 b$

Fig. $4 a$

Figure 4a-Humeral offset - measured from the geometric centre of the humeral head to the lateral edge of the greater tuberosity. Figure $4 b-$ Mean humeral offset in millimetres related to the clinical result.

N Normal shoulder $-33 \mathrm{~mm}(9$ cases $)$

E Excellent result $-26.5 \mathrm{~mm}(2$ cases

S Satisfactory result $-19 \mathrm{~mm}(3$ cases $)$

F Failure $-12.5 \mathrm{~mm} \quad(4$ cases $)$
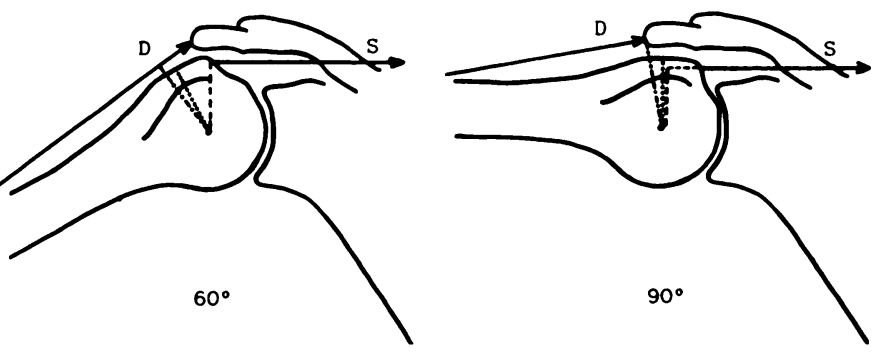

Fig. 5

Lever arm of supraspinatus

Line of muscle action

Diagrams to show the influence of the humeral offset on the lever arm of the deltoid (D) and the supraspinatus (S) at various angles of glenohumeral abduction (see text).
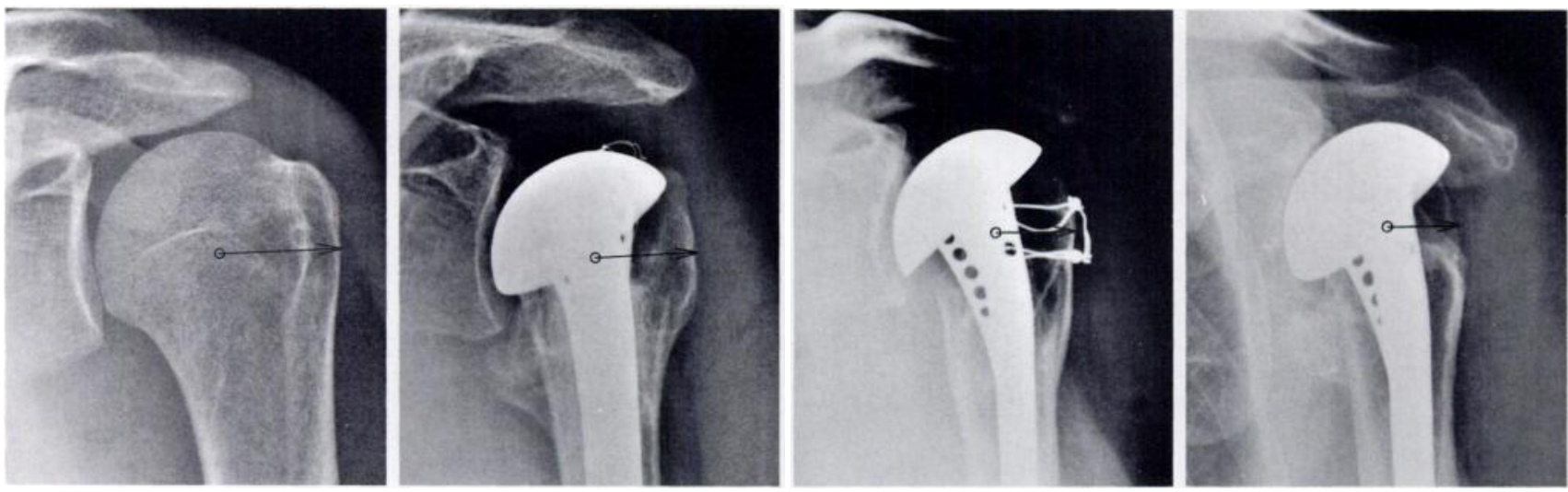

Fig. 6

Examples of humeral offset. From left to right, normal shoulder; Case 11, excellent result of Neer arthroplasty; Case 2, satisfactory result; Case 1, failure. 
The electromyographic results showed active contraction of the glenohumeral abductors and the lateral rotators of the scapula in all cases.

\section{DISCUSSION}

The average score of 76 points in our series is in the same range as the scores reported for other series (Neer 1970; Marotte et al. 1978; DesMarchais and Morais 1984; Stableforth 1984), results which have been described as "satisfactory, but imperfect" (Neer 1970). We found that the Neer prosthesis gave a reasonably painless shoulder and found no new clinical factors which influenced the result (Kraulis and Hunter 1976; DesMarchais and Morais 1984; Stableforth 1984). The Neer score gives most points for lack of pain, and it was obvious, even in our best cases, that loss of points for range of movement was mainly due to limited glenohumeral abduction (Table I). The EMG analysis showed that, even in our worse cases, contracting glenohumeral abductors were present.

If a cuff tear was the cause of the poor abduction, we would expect a clear relationship between the acromiohumeral interval and the result (Weiner and Macnab 1970). Furthermore, arthrography in one of our failures showed an intact rotator cuff, so its integrity does not seem to be an important factor.
The middle and some of the posterior fibres of the deltoid originate from the tip of the acromion. The lever arm through which these act depends on the lateral projection of the greater tuberosity, especially in the first $60^{\circ}$ of glenohumeral abduction (Howell et al. 1986) provided that it is lateral to the tip of the acromion (Fig. 5). If the greater tuberosity is medial to the line of the tip of the acromion as in all our hemiarthroplasties, the lever arm for the deltoid is reduced to zero and this can exert only an upward shear force. But even without deltoid action, some glenohumeral abduction should be possible (Van Linge and Mulder 1963; Markhede, Monastyrski and Stener 1985; Howell et al. 1986). An estimate for the lever arm of the supraspinatus would be helpful, because the supraspinatus is the only other glenohumeral abductor.

Although the humeral offset shown in Figure 4 does not represent the actual lever arm of the glenohumeral abductors, the diagrams in Figure 5 show its important influence on the lever arms of both supraspinatus (especially above $30^{\circ}$ glenohumeral abduction) and deltoid (especially below $60^{\circ}$ glenohumeral abduction). In the functionally important range of 30 to $60^{\circ}$ of glenohumeral abduction, it seems that the humeral offset is closely related to the lever arms of both muscles. A reduced humeral offset greatly reduces glenohumeral abduction power, and therefore the range of abduction

Table I. Clinical results in 14 cases after Neer hemiarthroplasty for four-part fracture

\begin{tabular}{|c|c|c|c|c|c|c|c|c|c|c|c|c|c|c|}
\hline Case number & 3 & 11 & 2 & 13 & 8 & 6 & 1 & 9 & 7 & 4 & 5 & 10 & 12 & 14 \\
\hline Neer score & 93 & 92 & 86 & 82 & 81 & 63 & 60 & 49 & 44 & 86 & 80 & 81 & 81 & 87 \\
\hline Result & $\mathrm{E}$ & $\mathrm{E}$ & $\mathbf{S}$ & $\mathbf{S}$ & $\mathbf{S}$ & $\mathbf{F}$ & $\mathrm{F}$ & $F$ & $F$ & $\mathbf{S}$ & $\mathbf{S}$ & $\mathbf{S}$ & $\mathbf{S}$ & $\mathbf{S}$ \\
\hline $\operatorname{Sex}$ & $\mathbf{M}$ & $\mathbf{M}$ & $\mathbf{M}$ & $\mathbf{F}$ & $\mathbf{F}$ & $\mathbf{F}$ & $\mathbf{M}$ & $\mathbf{F}$ & $F$ & $\mathbf{F}$ & $\mathbf{M}$ & $F$ & $\mathbf{F}$ & $\mathbf{F}$ \\
\hline Age (years) & 40 & 65 & 57 & 69 & 69 & 56 & 71 & 72 & 71 & 59 & 56 & 75 & 80 & 81 \\
\hline Follow-up (months) & 49 & 25 & 67 & 19 & 33 & 39 & 86 & 30 & 37 & 42 & 41 & 28 & 25 & 17 \\
\hline $\begin{array}{l}\text { Movement in degrees } \\
\text { Flexion active } \\
\text { passive }\end{array}$ & $\begin{array}{l}120 \\
140\end{array}$ & $\begin{array}{l}130 \\
150\end{array}$ & $\begin{array}{l}100 \\
100\end{array}$ & $\begin{array}{r}90 \\
110\end{array}$ & $\begin{array}{l}125 \\
125\end{array}$ & $\begin{array}{l}45 \\
60\end{array}$ & $\begin{array}{r}80 \\
100\end{array}$ & $\begin{array}{r}30 \\
100\end{array}$ & $\begin{array}{l}15 \\
60\end{array}$ & $\begin{array}{r}90 \\
100\end{array}$ & $\begin{array}{l}80 \\
90\end{array}$ & $\begin{array}{l}100 \\
170\end{array}$ & $\begin{array}{l}100 \\
130\end{array}$ & $\begin{array}{l}100 \\
120\end{array}$ \\
\hline $\begin{array}{c}\text { Abduction active } \\
\text { passive }\end{array}$ & $\begin{array}{l}120 \\
140\end{array}$ & $\begin{array}{l}130 \\
140\end{array}$ & $\begin{array}{l}100 \\
100\end{array}$ & $\begin{array}{l}80 \\
90\end{array}$ & $\begin{array}{l}100 \\
100\end{array}$ & $\begin{array}{l}55 \\
60\end{array}$ & $\begin{array}{l}80 \\
90\end{array}$ & $\begin{array}{l}50 \\
90\end{array}$ & $\begin{array}{l}30 \\
60\end{array}$ & $\begin{array}{l}80 \\
80\end{array}$ & $\begin{array}{r}80 \\
100\end{array}$ & $\begin{array}{l}100 \\
100\end{array}$ & $\begin{array}{l}110 \\
140\end{array}$ & $\begin{array}{l}80 \\
90\end{array}$ \\
\hline Medial rotation & 70 & 90 & 70 & 50 & 70 & 50 & 50 & 70 & 30 & 70 & 70 & 30 & 70 & 70 \\
\hline Lateral rotation & 60 & 25 & 30 & 40 & 30 & 15 & 30 & 30 & 25 & 30 & 10 & 20 & 30 & 45 \\
\hline
\end{tabular}

E excellent, $S$ satisfactory, $F$ failure.

Table II. Detailed radiological evaluation of the operated and normal sides in nine patients

\begin{tabular}{lrllllllll}
\hline Case number & 3 & 11 & 2 & 13 & 8 & 6 & 1 & 9 & 7 \\
\hline $\begin{array}{c}\text { Active movement in degrees } \\
\text { Glenohumeral operated } \\
\text { normal }\end{array}$ & 36 & 48 & 2 & 1 & 13 & -1 & 18 & -23 & -17 \\
$\begin{array}{c}\text { Scapular rotation operated } \\
\text { normal }\end{array}$ & 118 & 61 & 80 & 47 & 34 & 97 & 80 & 99 & 106 \\
$\begin{array}{c}\text { No } \\
\text { Humeral offset in mm operated } \\
\text { normal }\end{array}$ & 48 & 42 & 69 & 69 & 65 & 46 & 44 & 43 & 28 \\
& 26 & 27 & 21.5 & 14.5 & 22 & 14 & 17 & 6.5 & 15 \\
& 39 & 37.5 & 31 & 32 & 31 & 29.5 & 33.5 & 33 & 30.5 \\
\hline
\end{tabular}


and the quality of the clinical result. When the offset is small, the supraspinatus, in the important range of 30 to $60^{\circ}$ of abduction, will produce a compressive force at the glenohumeral joint, and the deltoid will produce an upward shear force (Poppen and Walker 1978). These abnormal forces result in loss of glenohumeral abduction, dynamic fixation of the glenohumeral joint and upward migration of the humeral head, as was seen in our hemiarthroplasty patients.

The lever arm principle applies to other shoulder conditions including osteosynthesis, other hemiarthroplasties and total shoulder replacements. Hemiarthroplasty for osteoarthritis of the shoulder may give better results than those after four-part fractures, because there is no bone loss, the integrity of the tuberosity is maintained and humeral offset is preserved (Neer 1974; de Anquin and de Anquin 1982). The principle of humeral offset has important implications for prosthetic design. Where there is severe loss of bone which cannot be restored with bone grafts then a more bulky prosthesis may be necessary. When it is not practicable to restore the humeral offset during hemiarthroplasty, then total replacement, using a superiorly extended, oversized glenoid component may be indicated (Bade et al. 1984). Such a superior extension will oppose the upward shear force of the deltoid, though this may give a greater risk of glenoid loosening. An oversized glenoid component will tend to hold the remains of the greater tuberosity out laterally so restoring the lever arm of the deltoid, and its abduction power. But an oversized glenoid component does not restore the lever arm of the supraspinatus, so some weakness will remain.

We conclude that poor function after hemiarthroplasty for four-part fractures is due to reduced lever arms for deltoid and supraspinatus. Restoration of the humeral offset will improve these levers and allow better function.

Our thanks are due to Mr Hans Fraterman and Mr Wim Deegenaars for their technical assistance in the orthopaedic laboratory, Mrs Jolanda Hofman-Hulsink for her secretarial work and to Mr Peter van de Pol for his enthusiastic co-operation.

No benefits in any form have been received or will be received from a commercial party related directly or indirectly to the subject of this article.

\section{REFERENCES}

de Anquin CE, de Anquin CA. Prosthetic replacement in the treatment of serious fractures of the proximal humerus. In : Bayley I, Kessel L, eds. Shoulder surgery. Berlin, etc: Springer-Verlag, 1982:207-17.

Bade HA III, Ranawat CS, Warren RF, Inglis AE. Long term results of Neer total shoulder replacement. In: Bateman JE, Welsh RP, eds. Surgery of the shoulder. Philadelphia, etc: BC Decker Inc. St Louis, etc: CV Mosby Co, 1984:294-302.

Freedman L, Munro RR. Abduction of the arm in the scapular plane: scapular and glenohumeral movements: a roentgenographic study. J Bone Joint Surg [Am] 1966;48-A :1503-10.

Howell SM, Imobersteg AM, Seger DH, Marone PJ. Clarification of the role of the supraspinatus muscle in shoulder function. $J$ Bone Joint Surg [Am] 1986;68-A:398-404.

Inman VT, Saunders JBdeCM, Abbott LC. Observations on the function of the shoulder joint. J Bone Joint Surg 1944;28:1-30.

Kraulis J, Hunter G. The results of prosthetic replacement in fracturedislocations of the upper end of the humerus. Injury 1976;8:129-31.

Lim TE, Ochsner PE, Marti RK, Holscher AA. The results of treatment of comminuted fractures and fracture dislocations of the proximal humerus. Neth J Surg 1983;35(4):139-43.

Van Linge B, Mulder JD. Function of the supraspinatus muscle and its relation to the supraspinatus syndrome: an experimental study in man. J Bone Joint Surg [Br] 1963;45-B:750-4.

DesMarchais JE, Morais G. Treatment of complex fractures of the proximal humerus by Neer hemiarthroplasty. In: Bateman JE, Welsh RP, eds. Surgery of the Shoulder. Philadelphia, etc: BC Decker Inc. St Louis, etc: CV Mosby Co, 1984;60-2.

Markhede G, Monastyrski J, Stener B. Shoulder function after deltoid muscle removal. Acta Orthop Scand 1985;56:242-4.

Marotte JH, Lord G, Bancel P. L'arthroplastie de Neer dans les fractures et fractures-luxations complexes de l'épaule: a propos de 12 cas. Chirurgie 1978;104:816-21.

Neer CS II. Displaced proximal humeral fractures. Part I. Classification and evaluation. J Bone Joint Surg [Am] 1970;52-A:1077-89.

Neer CS II. Displaced proximal humeral fractures. Part II. Treatment of three-part and four-part displacement. J Bone Joint Surg [Am] 1970;51-A:1090-103.

Neer CS II. Replacement arthroplasty for glenohumeral osteoarthritis. J Bone Joint Surg [Am] 1974;56-A :1-13.

Poppen NK, Walker PS. Normal and abnormal motion of the shoulder. J Bone Joint Surg [Am] 1976;58-A:195-201.

Poppen NK, Walker PS. Forces at the glenohumeral joint in abduction. Clin Orthop 1978;135:165-70.

Stableforth PG. Four-part fractures of the neck of the humerus. $J$ Bone Joint Surg [Br] 1984;66-B:104-8.

Weiner DS, Macnab I. Superior migration of the humeral head: a radiological aid in the diagnosis of tears of the rotator cuff. $J$ Bone Joint Surg [Br] 1970;52-B:524-7.

Willems WJ, Lim TEA. Neer arthroplasty for humeral fracture. Acta Orthop Scand 1985;56:394-5. 